\title{
A Mixed-Method Study on the Perceptions of Quality Management and Sustainability in Malaysian Hotel Industry
}

\author{
KIT-YENG SIN ${ }^{1}$, ABANG AZLAN MOHAMAD ${ }^{2}$, MAY-CHIUN LO ${ }^{3}$ \\ Faculty of Economics and Business, UNIVERSITI MALAYSIS SARAWAK, MALAYSIA. \\ ${ }^{1}$ E-mail: kysin@unimas.my \\ 2E-mail:maazlan@unimas.my \\ ${ }^{3}$ E-mail: mclo@unimas.my
}

\begin{abstract}
Rising trend of sustainability within tourism especially hotel industries remain ambiguous in many different areas of academic research and business. Nonetheless, contemporary relevance of quality practices and sustainability in the hotel industries has increased lately. This paper examined hotel quality managers (HQMs) perceptions of quality management and sustainability via the sequential-mixed methods approach, to bridge the gaps in the existing literature on the connection between pertinent variables. Therefore, in Phase 1 ten HQMs were deliberately selected and interviewed to perceive their views on quality management and the relationship between various quality management constructs towards sustainable performance. Phase 1 revealed that business ethics emerged as a new dimension, which needed to be emphasised. Subsequently, the qualitative results were utilised to design the hypotheses for $300 \mathrm{HQMs}^{\prime}$ quantitative surveys in Phase 2. The obtained survey data was analysed via the Partial Least Square-Structural Equation Models (PLS-SEM) to determine a list of hypotheses related to the impacts of key constructs. The present study depicted a significant and positive mediating connection between the HQMs perspective of quality management, business principles, and sustainable performance.
\end{abstract}

Keywords: quality management, sustainable performance, business ethics, hotel industries, mixed-methods design, Partial Least Square-Structural Equation Models (PLS-SEM)

JEL Classification: C1, L2

Recibido: 2 de Diciembre de 2020

Aceptado: 14 de Diciembre de 2020 


\section{Introduction}

Sustainability has progressively attracted the attentions of academicians and practitioners in various economic sectors around the world, particularly hotel industries for the past decades (Hussain, Al-Aomar \& Melhem, 2019). That is predominantly due to the fact that hotel industry is among the most environmentally detrimental industries, produces vast amounts of non-durable goods and waste water, consumes a lot of energy, and contributes to carbon emission (World Travel \& Tourism Council, 2019). All these activities leave a significant impact not only on the worldwide environment but also affect the economic and social dimensions extensively.

The concept of sustainability in Malaysia became a prominent post-economic crisis (Ashfaq \& Qureshi, 2020). Since the economic catastrophe, multiple organisations and the government have become highly aware of the importance of sustainability in Malaysia (Hassan, Noor \& Ramayah, 2020). Therefore, under the Eleventh Malaysian Plan (2016-2020), the nation's environmental agenda, specifically the tourism industry focused on protecting the environment to harness economic and social values from the process (Cohen et al., 2015b).

The Malaysian government supported hotel investment and granted the Investment Tax Allowance and Pioneer Status for newly-developed hotels with four or five-star ratings. (Malaysian Investment Development Authority, 2018). Despite the rapid expansion of 4-star and 5-star hotels in the country, reports proved that these hotels were not ready to exploit the global expertise to move Malaysia and Asia forward towards sustainable development and safeguard the planet as a result of the high implementation cost of green initiatives (Malaysian Investment Development Authority, 2018).

On the other hand, the rapid and revolutionary change within the hotel environment resulted in a challenging period for the management to comply with sustainable development (Sannassee et al., 2015). Furthermore, the external changes for instance economic evolution, worldwide market competition, and the existence of new technologies and information systems that are unperceivable had demotivated the participation of the hotel industries in the execution of sustainability (Kapera, 2018). These external changes brought about internal changes such as the transformation of management strategy and practises within the hotel entities (Kapera \& Wszendybyl-Skulska, 2017). As a result, the management had to implement multiple approaches, which included a significant implementation of Quality Management.

\section{Quality Management in Hotel Industries}

Quality Management emphasises on the improvement of service quality and the reduction of management costs (Changi et al., 2015). Besides, it also aims to offer clients outstanding merits through a continuous process of efficient restructuring (Changi et al., 2015). Furthermore, quality management helped hotels to attain a wide range of variations from its contenders, consumer satisfaction, brand acknowledgement, and cost savings that were linked to the cutback on waste (Junior, Lucado \& VanAllen, \& Jahoda, 2014). Therefore, quality management would be a viable approach to the contribution of sustainable performance (Junior et al., 2014).

As a result, issues on the implementation of quality management practices' impact on sustainable performance in the hotel sector are imperative to academic scholars, policymakers, and experts. Operations management requires finite academic work between operations management systems and the idea of sustainability in developing countries (Hallencreutz \& Turner, 2011). Besides, the evolution of quality management in the hotel industry had been thriving to meet the necessities of the exterior organisational frontiers and establishments, to generate production and sales growth and achieve consumer and stakeholders' satisfaction (Tasleem, Khan \& Masood, 2015). Therefore, it is necessary to conduct a comprehensive inquiry on the relationship between quality management and sustainable performance in the Malaysian hotel industry.

Nonetheless, limited research have been coordinated using a mixed methods approach to diffusely probe the quality management and sustainability phenomenon within hospitality context specifically hotel industry, which limits insightful interpretation on implementation of quality and sustainability 
practices from hotel industries' perspectives (Abbas, 2020; Stefano, Matteo, Francesco \& Giacomo, 2020; Hussain, et al., 2019). From a methodological viewpoint, this study makes an effort to fill in the research gaps by employing mixed methods approach, which can bring forth explicit and comprehensive answers with respect to degree and extent of quality management and sustainability phenomena within Malaysia's hotel industry. The focus of this study lies on the process for determining the new emerging dimensions that should be approached and implemented in such issue because of their direct and indirect relationship with sustainable performance using a mixed method research approach, specifically an exploratory sequential design, which will be discussed further in subsequent section.

\section{Research Method}

The sequential-mixed method was utilised to achieve an impactful and equalised analysis of the information as well as to validate the specific information via cross-verification of the qualitative and quantitative sources. (Creswell, 2014; Creswell \& Plano-Clark, 2011) posited that the mixed-methods offer practical knowledge, which is a useful tool in the process of decision-making and situation management.

First, this study focused on a qualitative investigation on 4 and 5-star hotel quality managers (HQMs) such as hotel quality executives or hotel operation managers' views of quality management and the relationship between constructs of quality and sustainable performance. HQMs currently or had once been responsible for the hotel's overall quality management programmes were selected to ensure that they could provide detailed information regarding their experiences and involvement in implementing quality programmes. Therefore, the responses were recorded word-for-word based on a semi-structured interview. Next, the data was analysed via the coding and interpretive assay stated below: The second phase utilised the survey research techniques, measurement, and Partial Least Square-Structural Equation Modelling (PLS-SEM). In the beginning, qualitative outcomes were employed to design a questionnaire, which was directed towards a large sample, and resulted in the expansion of quantitative construct measures and a theoretical paradigm. The hypotheses in the present study were designed based on the outcomes of the qualitative study and the literature review, which assessed the perceptions of HQMs on quality management. Besides, this study also examined the extent to which the confirmatory study supported the paradigm of structural relations, quality management constructs, and sustainable performance.

\subsection{Phase 1: An exploratory study of HQMs' perceptions of quality management and relationships among various quality management constructs towards sustainable performance}

\subsubsection{Issues explored}

The exploratory study was conducted to better understand HQMs' perceptions of quality management and how quality management influences sustainable performance. The following specific issues were explored:

- the relationship between quality management and sustainable performance

- additional important dimensions that were inherent in Malaysia's 4 and 5-star hotels

\subsubsection{Data Collection}

The present study invited several HQMs from the MAH Directory. These HQMs were hotel quality managers or hotel operation executives from 4 and 5-star hotels in the country. They were invited to join in the experimental study to support the relevance and viability of the obtained information (Lim et al. 2013). Finally, a total of 10 respondents were deliberately selected and interviewed. These respondents had the opportunity to involve in similar quality management practices, were well-versed in the subject matter, and were responsible for the execution of the hotel quality management plan. This study conducted an in-depth one-to-one semi-interview HQMs. Although a one-to-one interview 
is lengthy, pricey, and labour-intensive in comparison to focus group interviews (Creswell, 2012, p. 226), this method has few merits. First, it would have been arduous to gather all the sampled participants for a focus group interview because most of them were important figures in their organisation and were, therefore, often busy. Second, participants would have hesitated to share information openly during a focus group interview as a result of the competitive nature of the hotel industry (Creswell, 2012, p. 226).

In the present study, every interview was carried out for about 60-80 minutes. The respondents gave their consent and were permitted to walk out of the study anytime they wished to do so. The respondents were also well-informed about the confidential policy of the research. Therefore, their information and personal details would remain anonymous throughout the research.

\subsubsection{Analysis}

The interpretive method was utilised to examine the data and therefore, the reality was viewed as a collective construct. Individual responses were constantly constructed and decoded to provide an insightful elucidation of the mannerisms within a specific environment. The definitions were considered 'conceptualised, temporary knowledge' (Greene, 2000). Hence, the knowledge of the interpreter is debatable because it is context-based, complex, and signifies the interlinks between evidence and principles. Next, the interviews were transcribed and grouped according to the respective categories. The process of transliterating was arduous and therefore, these interviews were completed via Radnor's (2002) process of topic order. This method encouraged an inductive system of transcription. As a result, primary topics and new dimensions existed in the data. Finally, the present study analysed relationships as part and parcel of the listed categories.

\section{Results and Findings}

\subsection{Phase 1: Findings of the exploratory study}

A set of data was obtained from $10 \mathrm{HQMs}$ and classified based on their views on quality management. More than half of the respondents reported that the majority of the groups were themebased. About 4 groups were utilised to develop the hypotheses for the research prototype examined in the assented study of PLS-SEM.

\section{Quality Management and Sustainable Performance}

The respondents were conscious and could sufficiently explicate their comprehension of quality management. This could convalesce the implementation of sustainability. Based on this segment, different perspectives of quality management had facilitated respondents to contribute to sustainable performance in terms of economy, environment, and social.

Respondent 6:

"By adopting the quality management approach, we are very capable of sustaining economic and environmental aspects. We have gained tremendous brand image and become renowned in the public eye via quality inspections, waste minimalisation, and the implementation of strategies that meet standard requirement specifications."

Respondents 9 and 10:

"Quality management has made a significant contribution to the competitive advantage of promoting the company's environmental sustainability. Quality management also empowered us to minimise potential global warming gas (GWP) emissions, refrigerant emissions, to aid in the minimalisation of waste and pollution. In the future, these initiatives will contribute to the social, economic, and environmental sustainability."

The respondents delineated that quality management, which resulted in sustainable performance comprised of its outlook on the economic, environmental, and social aspects. These assertions were similar to the findings recorded by Abbas (2020), Hussain et al. (2019) and Stefano et al. (2020) in which 
practicing quality management supported the undertakings of the company sustainability. Based on the findings, the present study ascertained the impact between HQMs' views on quality management and their general perspective on sustainable performance. Next, the confirmatory study analysed the findings via the hypothesis below:

$\mathrm{H}_{1}$ : The quality management practices and sustainable performance depict a positive and significant relationship.

\section{Quality Management, Business Ethics, and Sustainable Performance}

Although respondents recommended the company to take initiatives related to daily quality management, the management should also pay more attention to ethics to ensure the organisation can sustain in the long-run. Nonetheless, each respondent had his or her perspective of balanced quality management and business principles and how these business principles can help intensify the relationship between quality management and sustainable performance in the hotel industry:

Respondent 2:

"Quality management can serve as a foundation and a catalyst to develop an ethics-based strategy, and analyse how strategies based on these two directions can contribute to the organisation's sustainable performance while improving the lives of the local community, labour intensives, and particularly society, as a whole."

Respondents 4 and 5:

"We have realised its significance (ethics) on time, both for business and for the community in which it operates. Consequently, the largest international hotel-chains have become advocates of ethical awareness in this industry. Bearing in mind its economic and environmental influence, the hotel sector is one of the most evident potential users of the application of ethical policies."

\section{Respondent 8:}

"Hoteliers like us must make sure that the ethical basis of quality is not neglected and that quality management takes a leading role in supporting ethical business practices. Therefore, these ethical principles are the core of quality management, which can influence and lead the formation of organisational values, and ultimately affect the vision and mission of corporate."

Business ethics exhibited newly emerging dimensions, which showed higher recurrences in the interview transcripts. Responses proved that the superior international is important to the industry and therefore, it is essential for hoteliers to conduct the right strategies for the business, to generate earnings only within the legal framework and keep in mind the rule: 'never deceive customers.' Hotel entities are not only expected to satiate the economic needs but are also required to pay more attention to environmental and social responsibilities related to stakeholders such as clients, employees, etc to reboot. Quality management alone is not enough to develop companies' sustainability. Therefore, respondents stated that business ethics is a necessary principle for the foundation of successful business establishing to attain entrepreneurial advancement.

The ethical practice focuses on the universal welfare of all stakeholders and it is considered equally fair. Therefore, the existence and practice of quality management will ultimately enhance these ethical behaviours to increase the importance of the associated outcomes and benefits. Additionally, empirical studies revealed that business ethics create external positive impacts on the financial and non-financial perspectives of business performances such as improved status and positive business reputation (Malik \& Kanwal, 2018), improved client allegiance (Huang \& Li, 2017) and develop viable benefits (Sarvaiya, Eweje \& Arrowsmith, 2018). Moreover, several studies highlighted the importance of business ethics between quality management and performance without an empirical test on their assertions (Shahzad, Ying, Ur Rehman, Zafar, Ding \& Abbas, 2019). Therefore, evidence proved that that business ethics can strengthen the quality management-based organisation to establish an ethically sensitive business culture that can gyrate towards sustainable hotel performance. Hence, a new dimension had been incorporated into the quantitative study to determine its effect on 
sustainability. As such, the following hypotheses were delineated from the findings in the present study:

$\mathrm{H}_{2}$ : Quality management and business ethics depict a positive and significant relationship.

$\mathrm{H}_{3}$ : Business ethics and sustainable performance depict a positive and significant relationship.

$\mathrm{H}_{4}$ : There is a positive mediating effect by business ethics in the relationship between quality management and sustainable performance.

\subsection{Phase 2: Research Model for the Confirmatory Study}

Figure 1 (Phase 2) depicts the theoretical framework extracted from Phase 1. The framework consisted of indicators such as quality management, business ethics, and sustainable performance that were used to examine the hypotheses.

Figure 1 Research model

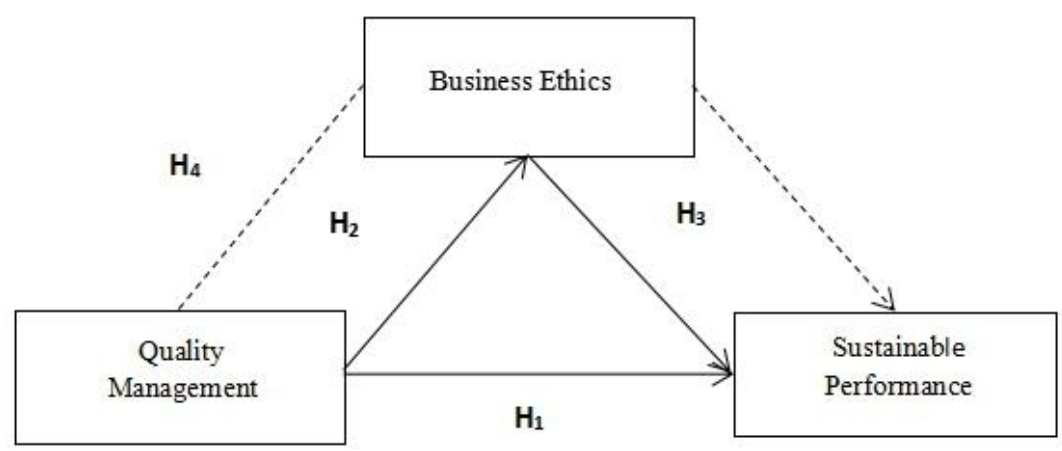

\subsubsection{Construct Measures}

The present research employed several survey tools to examine the variables of the research paradigm. These tools were predominantly extracted from the literature review and a qualitative study. Hence, the present study had listed the following constructs: Quality Management depicts the management-based modus operandi, which encourages the involvement of the entire team of the hotel industry to enhance procedures, products, services, and the culture, to achieve greater customer and stakeholders' satisfaction (Yusoff et al., 2016). Business ethics refers to the rules and principles that specify how individuals within the hotel entity should behave, despite the values that enhance and safeguard the welfare of the organisation, community, and society (ElGammal, El-Kassar \& Messarra, 2018). Sustainable performance refers to the enhanced perspectives of the hotel corporates to take into account issues such as environmental, social, and economy that are discussed in today's generation without negotiating the opportunity and capability for future generations (Abdul-Rashid et al., 2017).

The items of the dependent variable (sustainable performance), independent variables (quality management), and mediator (business ethics) were extracted from previous studies and was adapted based on the objectives of the current study. The present study utilised a 7-point Likert scale for all constructs that were measured between $1=$ strongly agree to $7=$ strongly agree (Joshi \& Rahman, 2015) or 1 = very low to 7 = very high (Yamaguchi, 1994). A 7-point Likert scale is an appropriate tool because it minimises the discrimination between the stimulus objects (Zikmund, Babin, Carr \& Griffin, 2010).

\subsubsection{Data Collection}

The hotel was used as the unit of analysis and all 4- and 5-star hotels operating in all the states in Malaysia were the sample population. According to MAH directory, in total, there were 275 4- and 5star hotels throughout Malaysia registered under them, in which 172 were 4-star hotels while 103 were 5-star hotels. Probability sampling - two stage stratified clustering sampling is adopted as 
sampling strategy, in which the stratum (4- and 5-star hotels) was divided into different clusters (states). Four states were selected at random, Klang Valley (Kuala Lumpur, Selangor, and Putrajaya), Johor, Melaka, and Penang, and sample was drawn from 4- and 5-star hotels within those states, as shown in Table 1. In line with Mohamed and Yusof (2009), the four states mentioned are the most prevalent choice for business, transitory, and vacation tourists; most local tourists will opt for Klang valley, Johor, Melaka, and Penang as their travel destinations. Since Klang valley, Johor, Melaka, and Penang comprise an adequate amount of 4- and 5-star rated hotels, this study selected these four places to distribute the questionnaire so that sufficient target respondents can be obtained. Based on Krejcie and Morgan's (1970) table, a total sample size of 162 HQMs were needed to represent Malaysian 4- and 5-star hotels. To ensure that the most reliable and valid number of respondents was obtained with no violations in sample size or normality, the researcher decided to apply more than the lowest required sample size recommended by statisticians. As such, 300 online questionnaires were sent out via electronic mail (email) to HQMs, using details obtained from each chosen hotel's human resource department.

Table 1 Two-stage Stratified Cluster Sampling Data

\begin{tabular}{lcccc}
\hline States & $\begin{array}{c}\text { Number of 4* and 5* } \\
\text { hotels }\end{array}$ & Calculation & Sample (\%) & $\begin{array}{c}\text { Sample } \\
\text { Size }\end{array}$ \\
\hline Klang valley & 94 & $94 / 165 * 162$ & 57 & 92 \\
Penang & 35 & $35 / 165 * 162$ & 21 & 34 \\
Johor & 21 & $21 / 165 * 162$ & 13 & 21 \\
Melaka & 15 & $15 / 165 * 162$ & 9 & 15 \\
Others & 110 & - & - & - \\
\hline Total & $\mathbf{2 7 5}$ & & $\mathbf{1 0 0}$ & $\mathbf{1 6 2}$ \\
\hline
\end{tabular}

\subsection{Phase 2: Results of the Confirmatory Study}

\subsubsection{Assessment of Measurement Model}

The examination of the measurement paradigm is made up of internal consistency reliability, convergent validity, and discriminant validity (Hair, Hult, Ringle \& Sarstedt, 2017). Hair, Black, Babin, \& Andersn (2010) defined internal consistency reliability as the extent to which objects assess the dormant constructs. However, composite reliability (CR) computes internal consistency better than the Cronbach's alpha (Hair et al., 2017). Although the CR value of " 0.6 is acceptable in exploratory research values above 0.95 indicate redundancy" (Avkiran \& Ringle, 2018, p. 4). The CR scores for all the constructs- Quality Management (0.889), Business Ethics (0.709) and Sustainable Performance $(0.830$ ) in the present study ranged between 0.709 to 0.889 (Appendix 1 ), which indicated the presence of the instrument's internal consistency reliability (Hair et al., 2014; Nunnally \& Bernstein, 1994).

Hair et al. (2017) defined convergent validity as the "extent to which a measure correlates positively with alternative measures of the same construct" (p.112). Therefore, the CV could be ascertained based on an examination of the exterior loading of the pointers' differences and the obtained average variance extracted (AVE) (Hair et al., 2014; Hair, Ringle, \& Sarstedt, 2011). The presence of an increased exterior loading depicted a highly illustrative indicator of the construct. In general, the rule states that at least $50 \%$ of each signifier's modification should be elucidated based on dormant variances. Subsequently, an indicator's exterior loading should surpass 0.078 because the digit when squared (0.708) should sum up to 0.50 . Nonetheless, overall, 0.7 is viewed as a suitable value for practical reasons (Hulland, 1999). Appendix 1 shows that the CV is confirmed when the outer loading of all constructs- Quality Management (0.79), Business Ethics (0.503) and Sustainable Performance (0.689) is adequate and the AVE of all constructs are equalised or have surpassed 0.50 (Hair et al., 2010).

The present study examined discriminant validity (DV) via the Heterotrait-Monotrait ratio of correlations (HTMT). Henseler, Ringle, and Sarstedt (2015) recommended the use of HTMT to evaluate DVs. Based on the predicted factor of correlation, the HTMPT should be lesser than one (preferably < 0.850) to differentiate between the two aspects (Henseler, Hubona, \& Ray, 2016). The outcomes of 
HTMT in the present study depicted that the constructs were between 0.440 and 0.816 . These digits were dramatically below the point of 1.0 and were established at HTMT.85. Therefore, Appendix 2 proved that all constructs were directly interdependent, which fulfilled the selection standards of DV.

Besides, the HTMT inferred results also indicate that the confidence interval $(\mathrm{CI})$ does not show a value of 1 in any of the constructs (Henseler et al., 2015), which confirms DV as well. The results of the overall measurement model demonstrate adequate internal consistency reliability, CV, and DV.

\subsubsection{Hypotheses Outcomes}

Results proved that the four hypotheses in the present study were reinforced based on the following data: quality management $\left(\mathrm{H}_{1}: \beta=0.908, \mathrm{t}=9.750, \mathrm{p}<0.01, \mathrm{LL}: 0.749, \mathrm{UL}: 0.912\right)$, had a positive connection with sustainable performance. Additionally, quality management $\left(\mathrm{H}_{2}: \beta=0.856, \mathrm{t}\right.$ $=21.187, p<0.01$, LL: 0.780, UL: 0.984) was imperatively related to business ethics. Besides, the outcomes for the coefficients of PLS depicted that business ethics $\left(\mathrm{H}_{3}: \beta=0.895, t=8.394, p<0.01, \mathrm{LL}\right.$ : 0.675 , UL: 0.796 ) had a positive impact on sustainable performance. Subsequently, Preacher and Hayes $(2004,2008)$ suggested an indirect method, which was applied to determine the mediating effect of business ethics between quality management and sustainable performance $\left(\mathrm{H}_{4}\right)$. The analysis portrayed the implicit impact, $\beta=0.424$ was imperative with a $t$-value of 2.975 . The secondary impact of the $95 \%$ Corrected Boot $\mathrm{Cl}$ Bias: [ $\mathrm{LL}=0.078, \mathrm{UL}=0.237$ ] did not overlap at 0 and indicated the presence of a mediation (Preacher \& Hayers, 2004, 2008). Therefore, the influence of mediation was statistically important, and business ethics $\left(\mathrm{H}_{4}: \beta=0.424, \mathrm{t}=2.975, \mathrm{p}<0.01, \mathrm{LL}: 0.078, \mathrm{UL}: 0.237\right)$ facilitated the connection between quality management and sustainable performance. Hence, Appendix 3 proved that the obtained results supported $\mathrm{H}_{1}, \mathrm{H}_{2}, \mathrm{H}_{3}$, and $\mathrm{H}_{4}$, respectively.

\section{Discussion}

The findings in this study revealed that the respondents believed that quality management has a positive influence on sustainability. These findings coincided with Ershadi, Najafi, and Soleimani's study (2019) whereby quality management helped minimise and sustain resources to achieve organisational sustainability. On the other hand, Alharbi, Al-Matari and Yusoff (2016) discovered that quality management was advantageous and achieved effective sustainability via processes, continuous improvement, customer satisfaction, and organisational commitment. In general, the study outcomes concurred with prior works of literature on quality management and its ability to predict sustainable performance. Therefore, the hypothesis revealed that there was a positive connection between quality management and sustainability in the Malaysian hotel industries $\left(\mathrm{H}_{1}\right)$.

Besides, study outcomes indicated that quality management was a significant predictor of business ethics $\left(\mathrm{H}_{2}\right)$. Therefore, efforts taken by the corporate world to enhance quality management would eventually improve ethical behaviours and increase the weight of the associated benefits because ethical practices impact the general welfare of the stakeholders (Phan et al., 2011). The results indicated that business ethics and quality management established a mutually beneficial relationship since quality cannot be successfully administered without taking into consideration ethics and moral principles, Therefore, the present finding is similar to previous research in which hoteliers who were genuinely committed towards quality management, established behavioural norms that were above their self-interests to safeguard the business without seeking any formal compensations or acknowledgement (Sadikoglu \& Olcay, 2014).

This study revealed that business ethics has a significant direct effect on sustainable performance $\left(\mathrm{H}_{3}\right)$. Previous studies reported a strong relationship between business ethics and sustainable performance (Bajaj, Thomas \& Mukherjea, 2014; Romar, 2014; Treviño \& Nelson, 2011), and the present study also identified similar relationship. Besides, previous studies claimed that ethics developed positive external influence such as investor loyalty and accountability, which assured durable positive economic outcomes (Malik et al., 2018), elevated image and positive business status 
(Huang et al., 2017), larger groups of committed clients (Sarvaiya et al., 2018), and building viable benefits (Romar, 2014).

Hence, good business ethics is a distinguishing quality that can bring unmeasured success to a commercial organization. In a similar vein, Du Mont (2015) affirmed that the culture of ethics had reduced misbehaviour and the stress of ethical standard negotiation, enhanced the act of reporting to the top authority and responded to misbehaviours. These actions had resulted in increased cooperation and teamwork within the organisation. Furthermore, Vujić, Ivaniš, and Bojić (2012) depicted that organisations with significant ethical commitments achieved intense stakeholder satisfaction, which had directly influenced the organisation's long-term prospects. Lastly, the results also confirmed the role of business ethics as the mediator between quality management and sustainable performance $\left(\mathrm{H}_{4}\right)$. This proved that business ethics is an important mechanism to convey the outcomes of quality management on sustainability in the hotel industry.

\section{Conclusion}

The findings of this study provide insight on the relationship between quality management practices, business ethics and sustainable performance specifically hotel industries in developing country, which may be different from that in developed countries. The current study will not only bridge the empirical gaps on the relationship between quality management practices, business ethics and sustainable performance but will also provide valuable insights to the academician proper procedures to explore new phenomena through sequential mixed method research design. The research framework developed in this study can be used as a guideline by hoteliers in developing countries to implement a new approach which incorporates quality management and business ethics into their strategic prioritization with full confidence based on their current conditions to achieve sustainable development goals. The new approach can be in any form of commendation, implementation and modification to assure that the sustainability strategies and key sustainability related to economic, environment and social aspects within hotel entities are addressed. This is to assure high standards of governance throughout the hotel operations to enhance responsible business practices, manage environmental impacts as well as to fulfill the social needs of communities and business operation.

The present study had surveyed 300 HQMs to examine their views on quality management and the relationship between business principles and sustainable performance that were executed in Malaysia, recently. Data were obtained from 4 and 5 -star hotels that were located in four distinctive states in Malaysia. Additionally, the HQMs samples collection exceeded the required sample size reckoned by Krejcie and Morgan (1970) for survey-based research considering a set of substantial quantitative data on construct procedures depicted assailable levels of relevance and legitimacy. Future research should conduct surveys on HQMs based on the different kinds of hotel proprietorship (domestic or foreign) or the specific categories of hotels such as business, resorts, and suites so that it can be explored that does hotel proprietorship or hotel categories matters to achieve sustainable performance objectives. Additionally, future research could focus on the characteristics of the personnel or organisation and their role as moderators (i.e., government support, technological advancement) in future work to estimate the ability of the suggested model.

\section{References}

1. Abbas, J. (2020). Impact of total quality management on corporate green performance through the mediating role of corporate social responsibility. Journal of Cleaner Production, 242, 118458.

2. Abdul-Rashid, S., Sakundarini, N., Raja Ghazilla, R., \& Thurasamy, R. (2017). The impact of sustainable manufacturing practices on sustainability performance. Int. J. Oper. Prod. Manag. 37 (2), 182-204. 
3. Alharbi, K., Al-Matari, E., \& Yusoff, R. (2016). The Impact of Total Quality Management (TQM) on organisational sustainability: The case of the hotel industry in Saudi Arabia: Empirical study. 11, 3468-3473.

4. Al-Ibrahim, A. (2014). Quality Management and Its Role in Improving Service Quality in Public Sector. Journal of Business and Management Sciences, 2(6), 123-147.

5. Ashfaq, M., \& Qureshi, M. I. (2020). Effect of Green Logistics on Sustainability Performance in Malaysia Manufacturing Companies. International Journal of Psychosocial Rehabilitation, 24, 784792.

6. Avkiran, N. K., \& Ringle, C. M. (2018). Partial least squares structural equation modeling: Recent advances in banking and finance. Heidelberg: Springer

7. Bajaj, M., Thomas, O., \& Mukherjea, U. (2014). A Bird's-eye View of DOJ's FCPA Fines and Settlements. Navigant Economics 1.

8. Changiz, V., \& Shervin R. (2015). The guidelines of improvement: Relations among organizational culture, TQM and performance. International Journal of Production Economics, 164 (C), 167-178.

9. Cohen, E., \& Cohen, S. A. (2015b). Beyond Eurocentrism in tourism: A paradigm shift to mobilities. Tourism Recreation Research, 40 (2), 157-168.

10.Creswell, J. W. (2012). Educational research: Planning, conducting, and evaluating quantitative and qualitative research (4th ed.). Boston, MA: Pearson.

11.Creswell, J. W. (2014). Research Design Qualitative, Quantitative, and Mixed Methods Approaches (4th ed., p. 304). Thousand Oaks, CA: SAGE Publications.

12.Creswell, J., \& Plano Clark, V. (2011). Designing and conducting mixed methods research. Thousand Oaks: Sage.

13.DeConinck, J. B. (2010). The effect of organisational justice, perceived organisational support, and perceived supervisor support on marketing. Journal of Business Research, 63, 1349-1355.

14.Du Mont, R. R. (2015). Ethics in librarianship: a management model. Library Trends, 40 (2), 201 215.

15.ElGammal,W., El-Kassar,A-N., \& Messarra,L.C. (2018). Corporate ethics, governance and social responsibility in MENA countries. Management Decision, 56 (1), 273-291.

16.Ershadi, M.J., Najafi, N., \& Soleimani, P. (2019). Measuring the impact of soft and hard total quality management factors on customer behaviour based on the role of innovation and continuous improvement. The TQM Journal, 31 (6), 1093-1115.

17.Greene, J. C., (2000). Qualitative program evaluation: practice and promise. in Denzin, N. K. and Lincoln, Y. S. (Eds.) Handbook of Qualitative Research. Thousand Oaks, California.

18.Hair, J.F., Black, W.C., Babin, B.J., \& Anderson, R.E. (2010). Multivariate Data Analysis. Seventh Edition. Prentice Hall, Upper Saddle River, New Jersey.

19.Hair, J., Hult, T., Ringle, C., \& Sarstedt, M. (2014). A Primer on Partial Least Squares Structural Equation Modeling (PLS-SEM). Thousand Oaks, CA: Sage Publications, Inc.

20.Hair, J.F., Hult, G.T.M., Ringle, C. M., \& Sarstedt, M. (2017). A Primer on Partial Least Squares Structural Equation Modeling (PLS-SEM), 2nd Ed., Sage: Thousand Oaks.

21.Hair, J. F., Ringle, C. M., \& Sarstedt, M. (2011). PLS-SEM: Indeed a Silver Bullet (November 4, 2011). Journal of Marketing Theory and Practice, 19 (2), 139-152. Available at SSRN: https://ssrn.com/abstract=1954735

22. Hallencreutz, J., \& Turner, D. M. (2011). Exploring organizational change best practice: are there any clear-cut models and definitions? International Journal of Quality and Service Sciences, 3 (1), 60-68.

23.Hassan, N-A., Noor, H.A., \& Ramayah, T. (2020). Entrepreneurial Leadership and Sustainable Performance of Manufacturing SMEs in Malaysia: The Contingent Role of Entrepreneurial Bricolage. Sustainability, MDPI, Open Access Journal, 12(8), 1-21.

24. Henseler, J., Hubona, G. S., \& Ray, P. A. (2016). Using PLS path modeling in new technology research: Updated guidelines. Industrial Management \& Data Systems, 116(1), 1-19. 
25. Henseler, J., Ringle, C.M., \& Sarstedt, M. (2015). A new criterion for assessing discriminant validity in variance-based structural equation modeling. Journal of the Academy of Marketing Science, 43(1), 115-135.

26. Huang, J.W., \& Li, Y.H. (2017). Green innovation and performance: the view of organizational capability and social reciprocity. J. Bus. Ethics, 145, 309-324.

27. Hulland, J. (1999). Use of partial least squares (PLS) in strategic management research: A review of four recent studies. Strategic Management Journal, 20, 195-204.

28.Hussain, M., Al-Aomar, R., \& Melhem, H. (2019). Assessment of lean-green practices on the sustainable performance of hotel supply chains. International Journal of Contemporary Hospitality Management, 31(6), 2448-2467

29.Joshi, Y., \& Rahman, Z. (2015). Factors Affecting Green Purchase Behavior and Future Research Directions. International Strategic Management Review, 3, 128-143.

30.Junior, M.V., Lucato, W.C., Vanalle, R.M., \& Jagoda, K.(2014). Effective management of international technology transfer projects: Insights from the Brazilian textile industry. Journal of Manufacturing Technology Management, 25(1), 69-99.

31.Kapera, I. (2018). Sustainable tourism development efforts by local governments in Poland, Sustainable Cities and Society, 40, 581-588.

32.Kapera, I., \& Wszendybyl-Skulska, E. (2017). Pro-ecological hotel policies as assessed by guest, Turyzm/Tourism, 27 (2), 57-62.

33.Krejcie, R.V., \& Morgan, D.W. (1970). Determining Sample Size for Research Activities. Educational and Psychological Measurement, 30, 607-610.

34.Kuei, C., \& Lu, M.H. (2013). Integrating quality management principles into sustainability management. Total Quality Management \& Business Excellence, 24(1/2), 62-78.

35.Lim, E.P., Chen, H.C., \& Chen, G.Q. (2013). Business Intelligence and Analytics: Research Directions. ACM Transactions on Management Information Systems. 3(4), 1-10. Research Collection School Of Information Systems

36. Malaysian Investment Development Authority (MIDA) (2018). available at: http://www.mida.gov.my/home/

37.Malik, M.S., \& Kanwal, L. (2018). Impact of corporate social responsibility disclosure on financial performance: case study of listed pharmaceutical firms of Pakistan. J. Bus. Ethics, 150, 69-78.

38. Mohamed, B., \& Yusof, Y. (2009). Malaysian Domestic Travelers: Characteristic And Behavior. Malaysia: Universiti Sains Malaysia.

39.Nunnally, J.C., \& Bernstein, I.H. (1994). The Assessment of Reliability. Psychometric Theory, 3, 248292.

40.Phan, A. C., Abdallah, A. B., \& Matsui, Y. (2011). Quality management practices and competitive performance: Empirical evidence from Japanese manufacturing companies. International Journal of Production Economics, 133(2), 518-529.

41.Preacher, K. J., \& Hayes, A. F. (2004). SPSS and SAS procedures for estimating indirect effects in simple mediation models. Behavior Research Methods, Instruments \& Computers, 36(4), 717-731.

42.Preacher, K.J., \& Hayes, A.F. (2008). Asymptotic and resampling strategies for assessing and comparing indirect effects in multiple mediator models. Behavior Research Methods, 40(3), 879891.

43.Radnor, H. A., (2002). Researching your professional practice: Doing interpretive research in educational settings. London: Open University Press.

44.Romar, E. J. (2014). Managerial harmony: The Confucian ethics of Peter F. Drucker. Journal of Business Ethics, 51(2), 199-210.

45.Sadikoglu, E., \& Olcay, H. (2014). The effects of total quality management practices on performance and the reasons of and the barriers to TQM practices in Turkey. Advances in Decision Sciences, 24(6), 948-975.

46.Sannassee, R. V., \& Seetanah, B. (2015). The influence of trust on repeat tourism: The Mauritian case study. Journal of Hospitality Marketing \& Management, 24(7), 770-789. 
47.Sarvaiya, H., Eweje, G., \& Arrowsmith, J. (2018). The roles of HRM in CSR: strategic partnership or operational support? J. Bus. Ethics, 153, 825-837.

48.Shahzad, M., Ying, Q., Ur Rehman, S., Zafar, A., Ding, X., \& Abbas, J. (2019). Impact of knowledge absorptive capacity on corporate sustainability with mediating role of CSR: analysis from the asian context. J. Environ. Plan. Manag., 1-27.

49.Stefano, F., Matteo G. C., Francesco C., \& Giacomo, D. C. (2020). Are you good enough? CSR, quality management and corporate financial performance in the hospitality industry. International Journal of Hospitality Management, 88, 102395.

50.Tasleem, M., Khan, N., \& Masood, S.A. (2015). Integrated Role of TQM and Technology Management in Organizational Sustainability. International Conference on Industrial Engineering and Operations Management, Dubai, UAE, 2015.

51.Trevino, L. K., \& Nelson, K. A. (2011). Managing business ethics: Straight talk about how to do it right. Hoboken, NJ: Wiley.

52.Vujić, V., Ivaniš, M., \& Bojić, B. (2012). Business Ethics and Multiculture. In Croatian. Fakultet za menadžment u turizmu i ugostiteljstvu, Opatija.

53.Wiengarten, F., \& Pagell, M. (2012). The importance of quality management for the success of environmental management initiatives. International Journal of Production Economics, 140(1), 407-415. http://dx.doi.org/10.1016/j.ijpe.2012.06.024

54.World Travel and Tourism Council, WTTC (2019). https://wttc.org/Research/Economic-Impact

55.Yamaguchi, S. (1994). Collectivism among the Japanese: A perspective from the self. In U. Kim, H. Triandis, C. Kağitçibaşi, S. Choi, \& G. Yoon (Eds.), Individualism and collectivism: Theory, method, and application, 175-188. Thousand Oaks, CA: Sage.

56.Yusoff, W., Aichouni, M., Badawi, I., \& Boujelbene, M. (2016). A survey on the implementation of Total Quality Management (TQM) at manufacturing industries in north region, Kingdom of Saudi Arabia. 2016 2nd International Conference on Information Management (ICIM), London, 84-88.

57.Zikmund, W. G., Babin, B. J., Carr, J. C., \& Griffin, M. (2010). Business research methods (8th ed.). Mason, HO: Cengage Learning. 
A Mixed-Method Study on the Perceptions of Quality Management and Sustainability in Malaysian Hotel Industry

Appendix 1 The Results of the Internal Consistency Reliability and CV of Measurement Model

\begin{tabular}{|c|c|c|c|c|c|}
\hline Construct & Items & $\begin{array}{l}\text { Factor } \\
\text { Loading }\end{array}$ & $\begin{array}{l}\text { Composite } \\
\text { Reliability }\end{array}$ & $\begin{array}{l}\text { Average Variance } \\
\text { (AVE) }\end{array}$ & Extracted \\
\hline \multirow{13}{*}{$\begin{array}{l}\text { Quality } \\
\text { Management }\end{array}$} & QM1 & 0.673 & \multirow{13}{*}{0.889} & \multirow{13}{*}{0.790} & \\
\hline & QM2 & 0.810 & & & \\
\hline & QM3 & 0.821 & & & \\
\hline & QM4 & 0.846 & & & \\
\hline & QM5 & 0.762 & & & \\
\hline & QM6 & 0.684 & & & \\
\hline & QM7 & 0.7701 & & & \\
\hline & QM8 & 0.803 & & & \\
\hline & QM9 & 0.669 & & & \\
\hline & QM10 & 0.772 & & & \\
\hline & QM11 & 0.805 & & & \\
\hline & QM12 & 0.792 & & & \\
\hline & BE1 & 0.737 & & & \\
\hline \multirow{10}{*}{ Business Ethics } & BE2 & 0.818 & \multirow{10}{*}{0.709} & \multirow{10}{*}{0.503} & \\
\hline & BE3 & 0.703 & & & \\
\hline & BE4 & 0.794 & & & \\
\hline & BE5 & 0.738 & & & \\
\hline & BE6 & 0.800 & & & \\
\hline & BE7 & 0.716 & & & \\
\hline & BE8 & 0.876 & & & \\
\hline & BE9 & 0.852 & & & \\
\hline & BE10 & 0.751 & & & \\
\hline & BE11 & 0.742 & & & \\
\hline \multirow{12}{*}{$\begin{array}{l}\text { Sustainable } \\
\text { Performance }\end{array}$} & SPERF1 & 0.733 & \multirow{12}{*}{0.830} & \multirow{12}{*}{0.689} & \\
\hline & SPERF2 & 0.625 & & & \\
\hline & SPERF3 & 0.653 & & & \\
\hline & SPERF4 & 0.821 & & & \\
\hline & SPERF5 & 0.785 & & & \\
\hline & SPERF6 & 0.759 & & & \\
\hline & SPERF7 & 0.678 & & & \\
\hline & SPERF8 & 0.745 & & & \\
\hline & SPERF9 & 0.746 & & & \\
\hline & SPERF10 & 0.781 & & & \\
\hline & SPERF11 & 0.719 & & & \\
\hline & SPERF12 & 0.725 & & & \\
\hline \multirow[t]{2}{*}{ Appendix 2} & \multicolumn{2}{|c|}{ HTMT Criterion } & & & \\
\hline & \multicolumn{2}{|c|}{$\begin{array}{l}\text { Quality } \\
\text { Management }\end{array}$} & Business Ethics & $\begin{array}{l}\text { Sustainable } \\
\text { Performance } \\
\end{array}$ & \\
\hline \multicolumn{4}{|c|}{ Quality Management } & & \\
\hline \multirow{3}{*}{ Business Ethics } & \multicolumn{2}{|c|}{0.755} & & & \\
\hline & \multirow{2}{*}{\multicolumn{2}{|c|}{$\begin{array}{l}\mathrm{Cl} .90 \\
(0.512 .0 .773)\end{array}$}} & & & \\
\hline & & & & & \\
\hline \multirow{3}{*}{$\begin{array}{l}\text { Sustainable } \\
\text { Performance }\end{array}$} & \multicolumn{2}{|c|}{0.606} & 0.613 & & \\
\hline & \multirow{2}{*}{\multicolumn{2}{|c|}{$\begin{array}{l}\mathrm{Cl} .90 \\
(0.3820 .791)\end{array}$}} & $\mathrm{Cl} .90$ & & \\
\hline & & & $(0.479,0.726)$ & & \\
\hline
\end{tabular}




\begin{tabular}{|c|c|c|c|c|c|c|}
\hline \multirow{2}{*}{ Hypotheses } & \multirow{2}{*}{$\beta$} & \multirow{2}{*}{$S E$} & \multirow{2}{*}{$t$ value } & \multicolumn{2}{|c|}{ Confidence Level } & \multirow{2}{*}{ Decision } \\
\hline & & & & $\mathrm{LL}$ & UL & \\
\hline $\begin{array}{l}\mathrm{H}_{1} \text { :Quality } \\
\text { Management } \rightarrow \text { Sustainable } \\
\text { Performance }\end{array}$ & 0.908 & 0.093 & $9.750 * *$ & 0.749 & 0.912 & Supported \\
\hline $\begin{array}{l}\mathrm{H}_{2} \text { :Quality } \\
\text { Management } \rightarrow \text { Business } \\
\text { Ethics }\end{array}$ & 0.856 & 0.039 & $21.187^{* *}$ & 0.780 & 0.984 & Supported \\
\hline $\begin{array}{l}\mathrm{H}_{3}: \text { Business } \\
\text { Ethics } \rightarrow \text { Sustainable } \\
\text { Performance }\end{array}$ & 0.895 & 0.077 & $8.394^{* *}$ & 0.675 & 0.796 & Supported \\
\hline $\begin{array}{l}\mathrm{H}_{4} \text { :Quality } \\
\text { Management } \rightarrow \text { Business } \\
\text { Ethics } \rightarrow \text { Sustainable } \\
\text { Performance }\end{array}$ & 0.424 & 0.068 & $2.975^{* *}$ & 0.078 & 0.237 & Supported \\
\hline
\end{tabular}

